\title{
Pharmacognostic Specifications, Quercetin and Quercitrin Quantification in Bauhinia malabarica Leaf
}

\author{
Paphitchaya Thetsana ${ }^{1}$, Chayanon Chaowuttikul' ${ }^{1}$, Chanida Palanuvej ${ }^{1}$, Nijsiri Ruangrungsi ${ }^{1,2, *}$
}

\section{Paphitchaya Thetsana', Chayanon Chaowuttikul', Chanida Palanuvej', Nijsiri Ruangrungsi ${ }^{1,2,{ }^{*}}$ Public Health Sciences Program, College of Public Health Sciences, Chulalongkorn University, Bangkok 10330, Thailand, ASIA. 2Department of Pharmacognosy, College of Pharmacy, Rangsit University, Pathum Thani12000, Thailand, ASIA.}

\section{Correspondence}

Dr. Nijsiri Ruangrungsi

College of Public Health Sciences, Chulalongkorn University, Bangkok 10330,

Thailand, ASIA.

Phone no : +662-218-8158

E-mail: nijsiri.r@chula.ac.th

\section{History}

- Submission Date: 25-06-2018;

- Review completed: 07-07-2018;

- Accepted Date: 22-10-2018

DOI : 10.5530/pj.2019.1.26

Article Available online http://www.phcogj.com/v11/i1

\section{Copyright}

(C) 2019 Phcog.Net. This is an openaccess article distributed under the terms of the Creative Commons Attribution 4.0 International license.

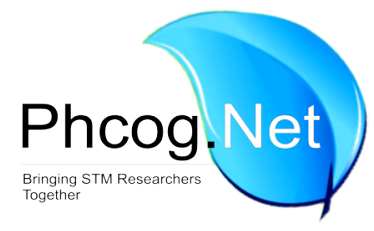

\begin{abstract}
Introduction: Bauhinia malabarica Roxb. is a tropical tree that found throughout Thailand. Leaves have a sour taste and have been used in Thai remedies for wound healing, diuretic, dysentery and emmenagogue. Objective: This study aimed to focus on pharmacognostic specification and quantitative analysis of quercetin and quercitrin in B. malabarica leaves. Methods: Various methods such as macroscopic and microscopic evaluations of $B$. malabarica leaf were studied along with physico-chemical parameters and quantitated quercetin and quercitrin using RP-HPLC. Results and Conclusion: Whole plant, structures of dried powder crude drug, cross section of midrib and leaf measurement were established. Paracytic stomata and multicellular trichome were found on lower epidermis. B. malabarica leaves from 15 sources throughout Thailand were examined the pharmacognostic specification according to WHO guideline. Physico-chemical parameters showed that loss on drying, total ash, acid insoluble ash and water content should not be more than 8.00, 7.08, 1.79 and $8.28 \%$ of dry weight while ethanol and water soluble extractive values should not be less than 13.78 and $16.47 \%$ of dry weight respectively. Quercetin and quercitrin were the markers for quantitative analysis using RP-HPLC with diode array detector in B. malabarica ethanolic extract. Quercetin and quercitrin contents were found to be $0.18 \mathrm{~g}$ and $0.38 \mathrm{~g}$ in $100 \mathrm{~g}$ of dried crude drug. Method validation was determined according to $\mathrm{ICH}$ guideline. All results were in the acceptable range and could be used for identity, safety, efficacy and quality of B. malabarica leaves in Thailand.
\end{abstract}

Key words: Bauhinia malabarica Roxb, Leaf measurement, Pharmacognostic specification, HPLC, Quercetin, Quercitrin.

\section{INTRODUCTION}

Bauhinia is a large genus of the family Leguminosae that approximately 300 species of trees, shrubs and climbers. This genus is native in tropical zones such as Africa, Asia and South America. They are commonly known as cow's paw or cow's hoof because of leaf shape. ${ }^{1}$ Mostly Bauhinia species are planted for showy flowers and ornamental shrubs. Bauhinia malabarica is a tropical tree that found throughout Thailand. Young leaves and flowers are edible. Leaves have a sour taste and have been used for wound healing, diuretic, dysentery and emmenagogue. Previous study, seven flavonol derivatives have been purified from B. malabarica leaves using chromatographic techniques such as 6,8-di-C-methylkaempferol 3 methyl ether, kaempferol, afzelin, quercetin, isoquercitrin, quercitrin and hyperoside. ${ }^{2}$ Quercetin is a flavonoid normally found in many fruits, vegetables, leaves and grains. The primary benefits of quercetin are possesses strongly antioxidant and anticancer. ${ }^{3}$ Quercitrin is a glycoside formed from quercetin and deoxy sugar rhamnose. Quercitrin has been demonstrated biological activities such as anti-inflammatory effect, preventing diarrhea and strongly anti-leishmanial activity. ${ }^{4}$ High performance liquid chromatography (HPLC) is a popular analytical technique used to separate, identify and quantify chemical compounds in medicinal plants. Pharmacognostic specification is the standard method to identify medicinal plants. Although, B. malabarica has been used to treat many diseases for a long time, but still lack of pharmacognostic study. Therefore, this study is focused on pharmacognostic specification and quantitative analysis of quercetin and quercitrin in B. malabarica leaves.

\section{MATERIALS AND METHODS}

\section{Plant collection}

B. malabarica fresh leaves were collected from Chulalongkorn University and dried leaves of B. malabarica were purchased from 15 traditional drugstores throughout Thailand. All plant samples were authenticated by one of the authors (Ruangrungsi, N.). Dried leaves were ground to fine powder and stored at College of Public Health Sciences, Chulalongkorn University. 


\section{Sample extraction}

Five grams of $B$. malabarica fine powdered were exhaustively extracted with 95\% ethanol using Soxhlet apparatus, filtered, the filtrate were evaporated to dryness and stored in refrigerator for quantitative quercetin and quercitrin using reverse phase high performance liquid chromatography (HPLC).

\section{Morphological examination}

B. malabarica fresh mature leaves were macroscopically and microscopically observed. Fine powder of B. malabarica leaves was mixed with a few drops of water on the slide and observed under microscope with the magnification of $10 \mathrm{x}$ to $40 \mathrm{x}$. The middle part of fresh mature leaf was cut into $0.5 \times 0.5 \mathrm{~cm}$, soaked in $50 \%$ sodium hypochlorite in water until clear, washed and boiled in chloral hydrate solution (4:1, chloral hydrate: water) until translucent, examined under microscope for palisade, trichome and epidermal cell numbers. Palisade cells in four epidermal cells were counted and divided by 4 for calculation palisade ratio. Trichome index and stomatal index were obtained from this formula ( $\mathrm{S}$ or $\mathrm{T} \times 100) /(\mathrm{S}+\mathrm{E}+\mathrm{T})$ whereas $\mathrm{S}=$ stomatal number, $\mathrm{E}=$ number of epidermal cells and $\mathrm{T}=$ trichome number. The midrib of $B$. malabarica fresh mature leaf was thinly cross-section with blade by hand and observed the anatomy under microscope with the magnification of $10 \mathrm{x}$ to $40 \mathrm{x}$.

\section{Physico-chemical characteristics}

Fine powder of B. malabarica dried leaves was examined for water content, loss on drying, ashes, extractive matters and volatile oil content according to "Quality control methods for medicinal plants materials" that established by World Health Organization (WHO). ${ }^{5}$ All samples were analyzed in triplicate. Grand mean and pooled standard deviation were calculated.

\section{Thin layer chromatographic fingerprint}

Three microliters of crude ethanolic extract solution were spotted onto the silica gel $\mathrm{GF}_{254}$ TLC plate. TLC plate was developed in saturated TLC chamber with toluene: acetone: chloroform: formic acid (2: 8: 8: 2). After development, the plate was observed under day light, UV $254 \mathrm{~nm}$, UV $365 \mathrm{~nm}$, stained with p-anisaldehyde and 1\% aluminium chloride in ethanol and detected under UV $365 \mathrm{~nm}$.

\section{HPLC analysis}

Shimadzu HPLC LC-20A system (Shimadzu, Japan) consists of system controller (CMB-20A), two solvent delivery units (LC-20A), an on-line degassing unit (DGU-20A ${ }^{3}$ ), an auto-sample (SIL-20A), a column oven (CTO-20A) and a photo-diode array detector (SPD-M20A). System control and data analysis were processed with Shimadzu LC Solution software. The chromatographic separation was performed with an Inertsil ${ }^{\circ}$ ODS-3 $5 \mu \mathrm{m}$ C18 column $(4.6 \times 250 \mathrm{~mm})$ coupled with ReproSil'-Pur ODS-3 C18 guard column $(4.0 \times 10 \mathrm{~mm})$. Solvent A was $0.5 \%$ phosphoric acid and solvent B was methanol (for RP-HPLC), filtered through $0.45 \mu \mathrm{m}$ nylon membrane filters and degasses before analysis. Isocratic mode was set as $50 \%$ solvent B for $30 \mathrm{~min}$, using flow rate $1.0 \mathrm{ml} / \mathrm{min}$, column temperature was set at $35^{\circ} \mathrm{C}$. Each B. malabarica ethanolic extract and standards (quercetin and quercitrin) were prepared in methanol, filtered through $0.45 \mu \mathrm{m}$ PTFE membrane syringe filter and injected $5 \mu$ l. Peak areas were observed under $255 \mathrm{~nm}$ and calculated using linear equations from calibration range of quercetin and quercitrin $(20,40,60,80$ and $100 \mu \mathrm{g} / \mathrm{ml})$.

\section{Method validation}

Calibration range, specificity, accuracy, repeatability, intermediate precision, limit of detection (LOD), limit of quantitation (LOQ) and robustness were examined following to the $\mathrm{ICH}$ guideline. ${ }^{6}$

\section{RESULTS AND DISCUSSION}

\section{Morphological examination}

B. malabarica Robx. leaves are green color on both sides. The leaf shape was is bilobed, rough surface, thick leaf, $6-10 \mathrm{~cm}$ wide, $5-7 \mathrm{~cm}$ long (Figure 1) and sour taste. Flowers are small white or light green.

Powdered of B. malabarica leaves consist of multicellular trichome, paracytic stomata, epidermis, spiral vessel, prism of calcium oxalate and fibers (Figure 2). Microscopic leaf constant numbers including epidermal cell area, stomatal number, stomatal index, trichome number, trichome index and palisade ratio were shown in Table 1. Anatomical characteristic of $B$. malabarica leaf (midrib part cross section) was shown in Figure 3. Physico-chemical properties of $B$. malabarica dried leaves including water content, ethanol soluble extractive, water soluble extractive, loss on drying, total ash, acid insoluble ash and volatile oil content were demonstrated in Table 2.

Plants extracts can provide a chromatographic "fingerprint" used for identification purposes. The colors of the separated spots and their position relative to standard substances are important characteristics for the plant extract identification. ${ }^{7}$ In this study, TLC fingerprint was the preliminary identification of B. malabarica (Figure 4).

Pharmacognostic parameters were shown the specific characteristics of $B$. malabarica leaf constant numbers. In morphological examination part, the specific character of B. malabarica leaves was sour taste, only this species has the sour taste, so, unknown sample which looks like B. malabarica needs to be tasted in the first step. Another specific character was not only multicellular trichome and paracytic stomata on lower epidermis, but also the average of palisade ratio. Palisade ratio is the diagnostic value in differentiating the species and dose not based on geographical variations. ${ }^{8}$

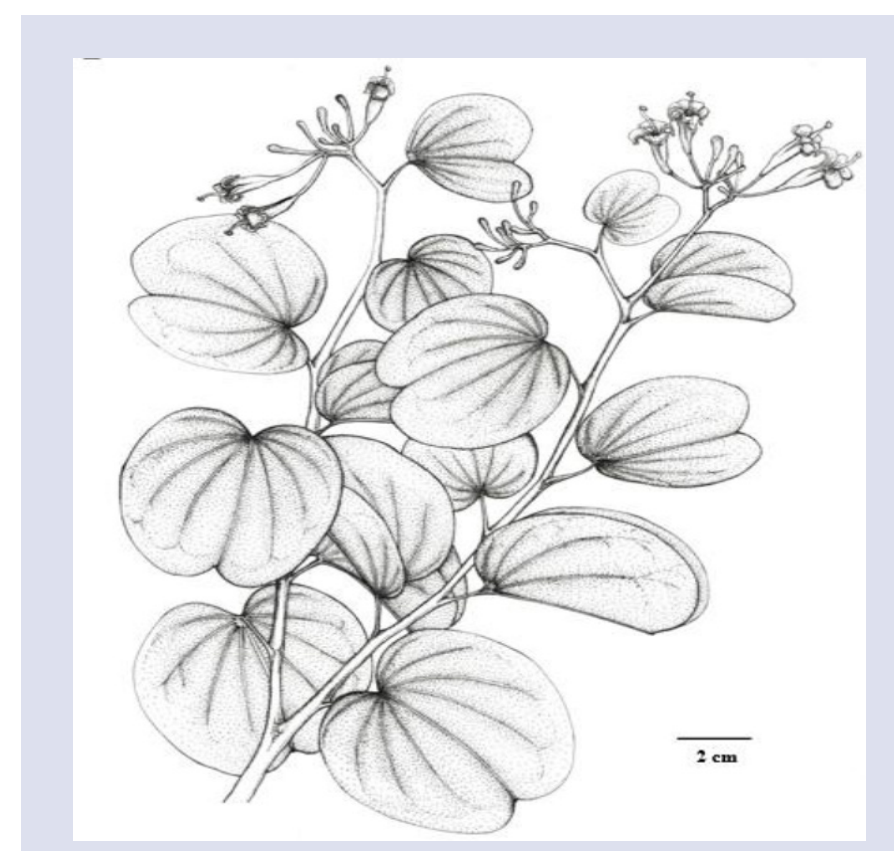

Figure 1: Branch of B. malabarica Roxb. 

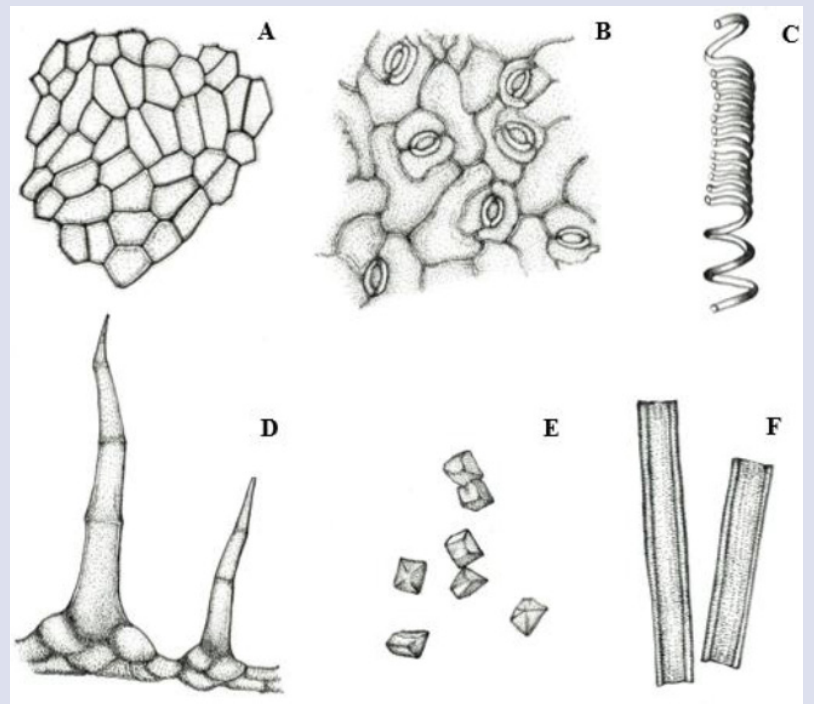

$0.1 \mathrm{~mm}$

Figure 2: Histological characteristics of $B$. malabarica leaf powder consists of $A=e$ idermis, $B=$ paracytic stomata, $C=$ spiral vessel, $\mathrm{D}=$ multicellular trichome, $\mathrm{E}=$ prism of calcium oxalate, $\mathrm{F}=$ fiber.

Table 1: Microscopic leaf constant numbers of B. malabarica leaves.

\begin{tabular}{cc}
\hline Parameter & Mean \pm SD \\
\hline Epidermal cell area $\left(\mu \mathrm{m}^{2}\right)$ & $685.912 \pm 8.592$ \\
Stomatal number $\left(/ \mathrm{mm}^{2}\right)$ & $683.867 \pm 18.179$ \\
Stomatal index & $18.066 \pm 0.431$ \\
Trichome number $\left(/ \mathrm{mm}^{2}\right)$ & $12.800 \pm 3.547$ \\
Trichome index & $0.338 \pm 0.092$ \\
Palisade ratio & $3.767 \pm 0.236$ \\
\hline
\end{tabular}

Table 2: Physico-chemical parameters of B. malabarica dried leaves.

\begin{tabular}{cc}
\hline Parameter & Content (\% by weight) \\
\hline Water content & $8.280 \pm 0.407$ \\
Ethanol soluble extractive & $13.781 \pm 0.197$ \\
Water soluble extractive & $16.474 \pm 0.389$ \\
Loss on drying & $7.998 \pm 0.046$ \\
Total ash & $7.079 \pm 0.047$ \\
Acid insoluble ash & $1.788 \pm 0.184$ \\
Volatile oil content & 0 \\
\hline
\end{tabular}

${ }^{*}$ The parameters were shown as grand mean \pm pooled standard deviation. Samples were from 15 different places throughout Thailand and each sample was done in triplicate.

\section{HPLC analysis}

The content of quercetin and quercitrin in B. malabarica dried leaves were shown in Table 3 . The content values were calculated and shown as grams of quercetin or quercitrin per 100 grams of dried crude drug. The different values of quercetin or quercitrin in B. malabarica leaf ethanolic extract were depended on the geographic variation that affected to secondary metabolite of plants. ${ }^{9}$

\section{Method validation}

The method validation parameters of reversed phase high performance liquid chromatography were optimized by performing the effect of the mobile phase and detection wavelength on resolution and sensitivity. An isocratic elution method was shown good separation in both standard and B. malabarica ethanolic extract. In this study, the range of absorbance $(200-800 \mathrm{~nm})$ was screened in both quercetin and quercitrin, the

Table 3: The contents of quercetin and quercitrin in B. malabarica leaves.

\begin{tabular}{cccc}
\hline \multirow{2}{*}{ No. } & $\begin{array}{c}\text { \% yield } \\
(\mathbf{g} / 100 \mathrm{~g})\end{array}$ & \multicolumn{2}{c}{ Content $(\mathrm{g} / 100 \mathrm{~g}$ of dried crude drug) } \\
\cline { 3 - 4 } 1 & 27.382 & $0.1783 \pm 0.0005$ & $0.6002 \pm 0.0012$ \\
2 & 26.691 & $0.1630 \pm 0.0003$ & $0.6932 \pm 0.0006$ \\
3 & 29.267 & $0.1330 \pm 0.0002$ & $0.2904 \pm 0.0003$ \\
4 & 26.862 & $0.1141 \pm 0.0000$ & $0.1436 \pm 0.0002$ \\
5 & 30.579 & $0.0988 \pm 0.0003$ & $0.1089 \pm 0.0001$ \\
6 & 25.115 & $0.1501 \pm 0.0004$ & $0.2454 \pm 0.0005$ \\
7 & 18.471 & $0.0715 \pm 0.0001$ & $0.7512 \pm 0.0007$ \\
8 & 23.262 & $0.1517 \pm 0.0003$ & $0.2642 \pm 0.0008$ \\
9 & 29.887 & $0.2724 \pm 0.0004$ & $0.3053 \pm 0.0002$ \\
10 & 26.199 & $0.1918 \pm 0.0006$ & $0.3740 \pm 0.0002$ \\
11 & 26.657 & $0.2214 \pm 0.0004$ & $0.2125 \pm 0.0003$ \\
12 & 29.908 & $0.2844 \pm 0.0005$ & $0.2787 \pm 0.0001$ \\
13 & 25.429 & $0.1535 \pm 0.0008$ & $0.7062 \pm 0.0002$ \\
14 & 24.184 & $0.2100 \pm 0.0008$ & $0.2528 \pm 0.0000$ \\
15 & 29.302 & $0.3004 \pm 0.0002$ & $0.5233 \pm 0.0005$ \\
\hline
\end{tabular}

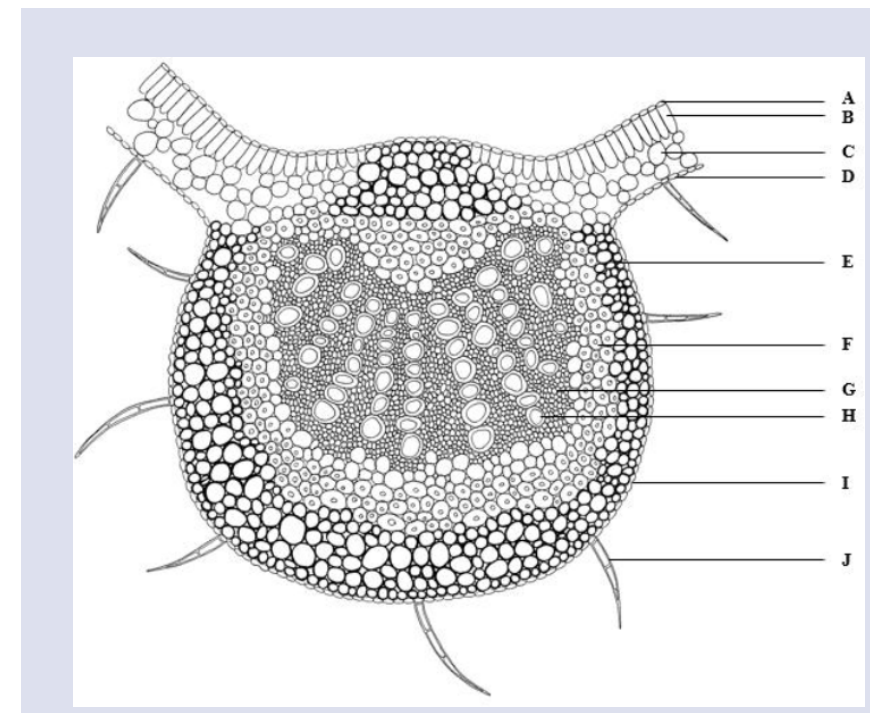

Figure 3: Anatomical characteristics of $B$. malabarica leaf (midrib part cross section) consists of $A=$ upper epidermis, $B=$ palisade cells, C=sponge cells, $\mathrm{D}=$ lower epidermis, $\mathrm{E}=$ collenchyma, $\mathrm{F}=$ scherenchyma cells, $\mathrm{G}=$ phloem, $\mathrm{H}=x y l e m, \quad \mathrm{I}=$ stomata, $\mathrm{J}=$ multicellular trichome. 


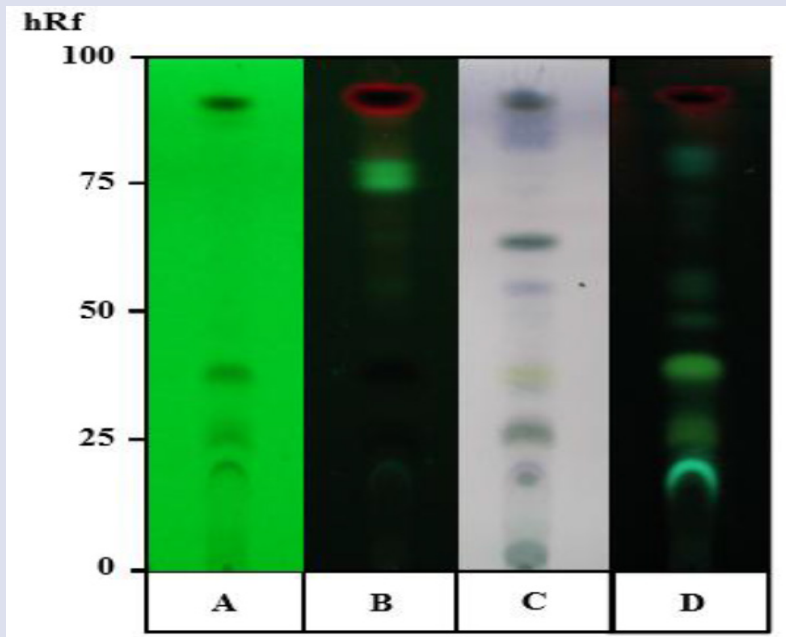

Figure 4: TLC fingerprint of $B$. malabarica leaf ethanolic extract; $\mathrm{A}=$ detection under UV $254 \mathrm{~nm}, \mathrm{~B}=$ detection under UV $365 \mathrm{~nm}$, $\mathrm{C}=$ stained with $\mathrm{p}$-anisaldehyde and $\mathrm{D}=$ stained with $1 \%$ aluminium chloride and detected under UV $365 \mathrm{~nm}$.

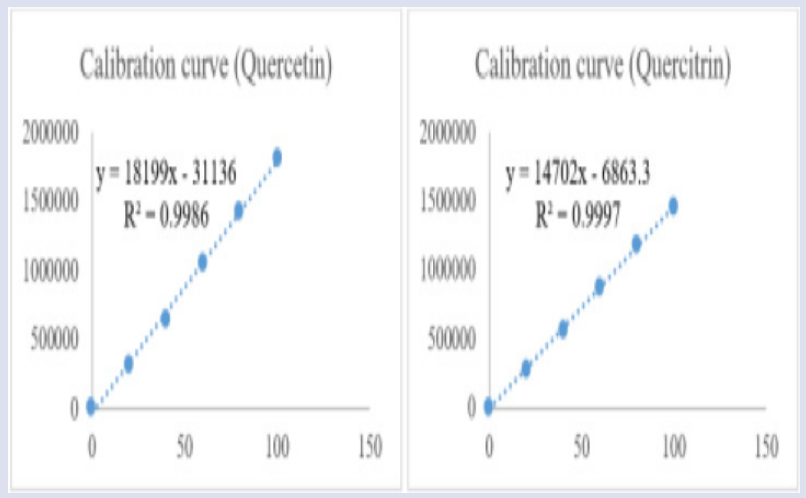

Figure 5: The calibration curve of quercetin and quercitrin.

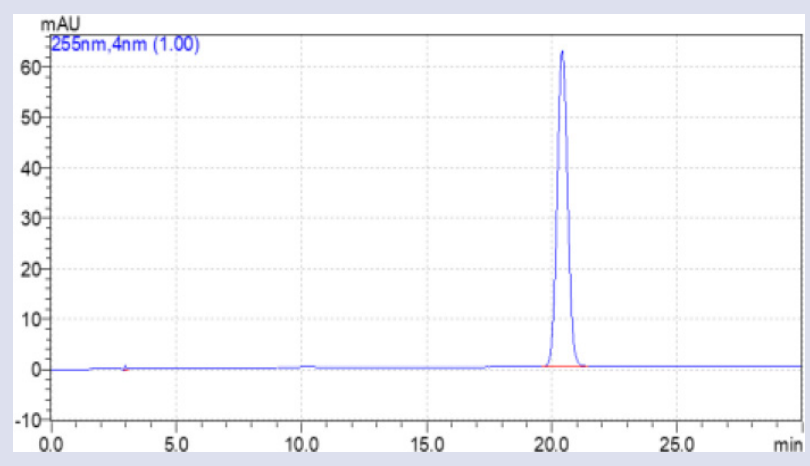

Figure 6: HPLC chromatograms of standard quercetin at $255 \mathrm{~nm}$ by HPLC-DAD.

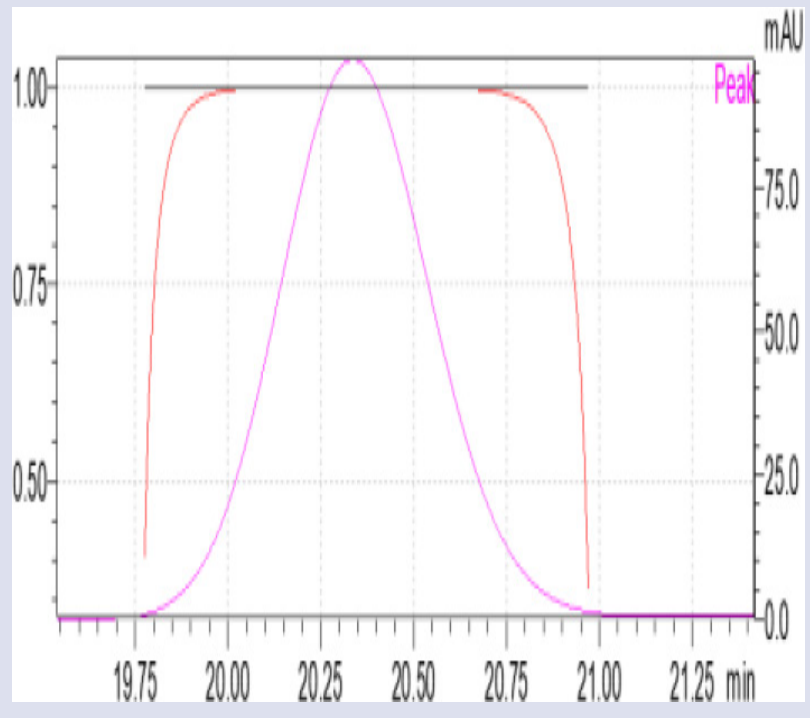

Figure 7: The peak purity of quercetin in B. malabarica leaf ethanolic extract.

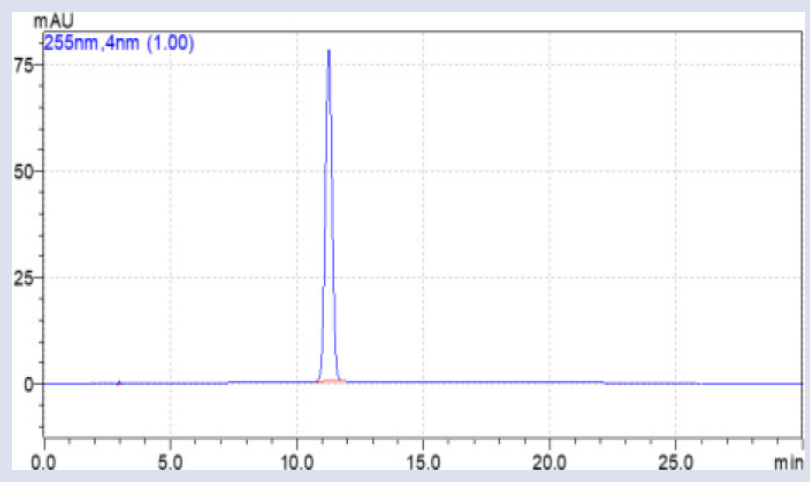

Figure 8: HPLC chromatograms of standard quercitrin at $255 \mathrm{~nm}$ by HPLC-DAD.

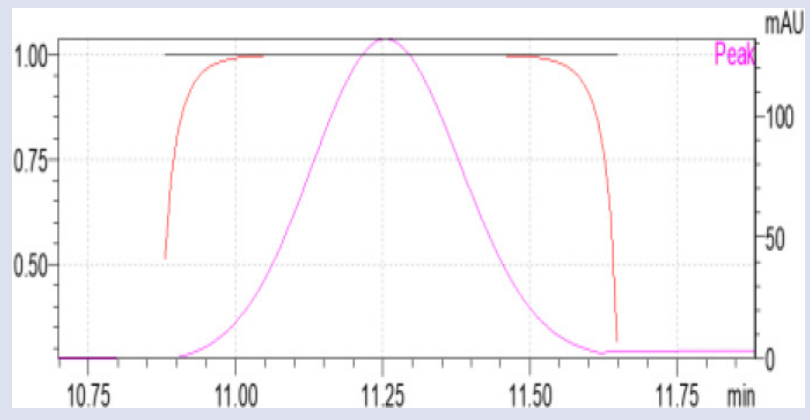

Figure 9: The peak purity of quercitrin in B. malabarica leaf ethanolic extract. 
result was shown that the detection wavelength at $255 \mathrm{~nm}$ was presented the optimum absorbance wavelength.

Linear calibration curves in the range of $20,40,60,80$ and $100 \mu \mathrm{g} / \mathrm{ml}$ were created for each compound by plotting the peak area with the concentration. The regression equation of quercetin and quercitrin were $y=18199 x-31136$ and $y=14702 x-6863.3$. The linear demonstrated excellent correlation as 0.998 in quercetin and 0.999 in quercitrin respectively (Figure 5). The correlation of method $\left(\mathrm{R}^{2}\right)$ value was reached 0.99 which mean that this analytical technique is acceptable. ${ }^{10}$

The peaks of quercetin and quercitrin were well separated at different retention times with resolutions of 20.324 and 11.245, respectively. No interferences or excipient peaks co eluted with the analytes were observed, indicating the method is selective and specific in this study. ${ }^{11}$

Peak purity test was based on absorbance spectrum using diode array detector which confirmed the mobile phase was suitable for analyte chromatographic peak that showed a good separation from another compound. If all the individual spectra recorded during elution of a peak are identical even detected at any periods of peak, the peak is considered as absolutely pure. ${ }^{12}$ Peak purity index of quercetin and quercitrin showed more than 0.999 (Figure 7, 8 and 9), it demonstrated that all peaks were pure.

The accuracy was determined by recovery method which spiked three concentrations $(20,40$ and $60 \mu \mathrm{g} / \mathrm{ml})$ of standard quercetin and quercitrin into B. malabarica leaves ethanolic extract, acceptable of \%recovery is between $80-120 \%,{ }^{6}$ the results ranged from $97.378-99.177$ and 98.181 $-102.288 \%$ recovery as shown in the Table 4 . The precision, both repeatability and intermediate precision were done on spiked sample with three different concentrations in the same day and three different days. The result of $\%$ RSD was determined the error of the method, acceptable of \%RSD was not more than $15 \%$ RSD. ${ }^{13}$ The result of repeatability and intermediate precision in quercetin and quercitrin were shown in Table 4. The residual standard deviation of a regression line and the slope of calibration range in both quercetin and quercitrin were used to calculate LOD and LOQ analysis. LOD and LOQ of quercetin were 4.755 and $14.408 \mu \mathrm{g} / \mathrm{ml}$ and 1.941 and $5.883 \mu \mathrm{g} / \mathrm{ml}$ in quercitrin, respectively.

Table 4: Accuracy and precision of quercetin and quercitrin in B. malabarica leaves.

\begin{tabular}{|c|c|c|c|c|}
\hline \multirow[b]{2}{*}{ Compounds } & \multirow[b]{2}{*}{$\begin{array}{c}\text { Spike } \\
\text { concentration } \\
(\mu \mathrm{g} / \mathrm{ml})\end{array}$} & \multirow[b]{2}{*}{$\begin{array}{c}\% \\
\text { recovery } \\
(n=3)\end{array}$} & \multicolumn{2}{|c|}{$\%$ RSD } \\
\hline & & & $\begin{array}{l}\text { Repeatability } \\
\text { precision } \\
(n=3)\end{array}$ & $\begin{array}{l}\text { Intermediate } \\
\text { precision } \\
(n=3)\end{array}$ \\
\hline \multirow{3}{*}{ Quercetin } & 20 & 97.390 & 1.150 & 2.947 \\
\hline & 40 & 97.378 & 1.496 & 2.522 \\
\hline & 60 & 99.177 & 1.164 & 1.519 \\
\hline \multirow{3}{*}{ Quercitrin } & 20 & 98.610 & 1.432 & 0.813 \\
\hline & 40 & 98.181 & 1.548 & 2.947 \\
\hline & 60 & 102.288 & 1.432 & 1.130 \\
\hline
\end{tabular}

${ }^{*} \mathrm{n}=$ triplicated

Table 5: Robustness of quercetin and quercitrin in B. malabarica leaves.

\begin{tabular}{ccccccc}
\hline \multirow{2}{*}{ Compounds } & \multicolumn{5}{c}{ \% RSD of sample } \\
\cline { 2 - 7 } & \multicolumn{2}{c}{ Flow rate } & \multicolumn{2}{c}{ Temperature } & \multicolumn{2}{c}{ Wavelength } \\
\cline { 2 - 7 } & Rt & Area & Rt & Area & Rt & Area \\
\hline Quercetin & 4.051 & 6.785 & 3.028 & 6.848 & 0.087 & 2.553 \\
Quercitrin & 4.011 & 7.043 & 2.602 & 6.643 & 0.128 & 1.863 \\
\hline
\end{tabular}

${ }^{\star} \mathrm{R} t=$ Retention time
The slightly changes of column temperature, flow rate and wavelength were calculated from one sample for robustness method. Column temperature was varied from $34-36^{\circ} \mathrm{C}$, the flow rate was set in the range of $0.950-1.050 \mathrm{ml} / \mathrm{min}$ and the detection wavelength was defined at $252 \mathrm{~nm}, 255 \mathrm{~nm}$ and $258 \mathrm{~nm}$ in both quercetin and quercitrin. The results were shown in the Table 5. The variations of column temperature, flow rate and detection wavelength were demonstrated that there were no differences $(\% \mathrm{RSD}<8)$ in the retention time and the area of the curve of quercetin and quercitrin. So, the robustness was showed reliably of the method. ${ }^{10}$

\section{CONCLUSION}

The characters of B. malabarica leaves according to macroscopic and microscopic evaluations, leaf measurement, physico-chemical parameters and RP-HPLC analysis shall be useful to identity and characterized the safety, efficacy and quality in the further use and studies.

\section{ACKNOWLEDGEMENT}

The authors thank College of Public Health Sciences, Chulalongkorn University for Teaching Assistant Scholarship, necessary assistance and instrument supports.

\section{CONFLICT OF INTEREST}

The authors declare no conflict of interest.

\section{ABBREVIATIONS}

RP-HPLC: Reversed phase high performance liquid chromatography; S: Stomatal number; E: Number of epidermal cells; T: Trichome number; $\mu^{2}$ : Square micrometer; $\mathbf{m m}^{2}$ : Square millimeter; Rt: Retention time.

\section{REFERENCES}

1. Filho VC. Chemical composition and biological potential of plants from the genus Bauhinia. Phytotherapy research. 2009;23(10):1347-54.

2. Kaewamatawong R, Kitajima M, Kogure N, Takayama H. Flavonols from Bauhinia malabarica. Natural Medicine Note. 2008;62(3):364-65

3. Prasain JK, Jones K, Moore R, Barnes S, Leahy M, Roderick R, et al. Effect of cranberry juice concentrate on chemical-induced urinary bladder cancers. Oncology Reports. 2008;19:1565-70.

4. Ding M, Zhao J, Bowman L, Lu Y, Shi X. Inhibition of AP-1 and MAPK signaling and activation of Nrf2/ARE pathway by quercitrin. International Journal of Oncology. 2010;36(1):59-67.

5. World Health Organization. Quality control methods for medicinal plant materials. Geneva: WHO Press. 2011.

6. ICH (Q2R1) Validation of analytical Procedures: Text and Methodology. Geneva: International Conference on Harmonization, International Conference on Harmonization of Technical Requirements for registration of Pharmaceuticals for Human Use. 2005

7. Cazes J. Encyclopedia of Chromatography. Florida: Florida Atlantic University. 2009.

8. Mukherjee P. Microscopical evaluation. In: Quality control of herbal drugs: an approach to evaluation of botanicals. New Delhi, India: Business horizons. 2002;178.

9. Smriti M, Shashidhara S, Rajasekharan PE, Hanumantharaju N, Rajendra CE. HPLC analysis of Adhatoda vasica obtained from different geographical sources. International Journal of Drug Development and Research. 2010;2(4):676-80.

10. Duangyod, T, Palanuvej C, Ruangrungsi N. Pharmacognostic specifications and quantification of $(+)$-catechin anf (-)-epicatechin in Pentace burmanica stem bark. Pharmacognosy Research. 2014;6(3):251-6.

11. Ang LF, Yam MF, Fung YT, Kiang PK, Darwin Y. HPLC method for simultaneous quantitative detection of quercetin and curcuminoids in traditional Chinese medicines. Journal of Pharmacopuncture. 2014;17(4):36-49.

12. Papadoyannis IN, Gika HG. Peak purity determination with a diode array detector Encyclopedia of Chromatography. 2003;1-5.

13. U.S. Department of Health and Human Services. Guidance for Industry: Bioanalytical Method Validation. Maryland, U.S. Food and Drug Administration. 2001. 
GRAPHICAL ABSTRACT

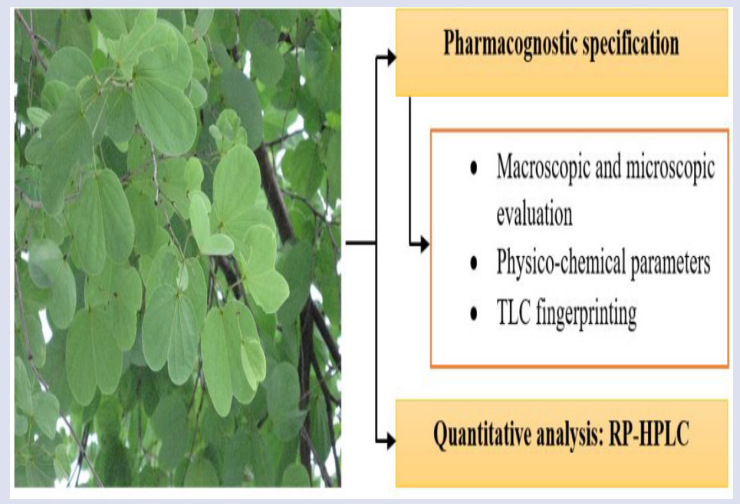

\section{SUMMARY}

- Bauhinia malabarica Roxb. is a species in family Leguminosae. It has been widely used as medicinal plants for a long time. In Thailand, B. malabarica leaves is locally used to treat wound healing, diuretic, dysentery and emmenagogue.

- This study focused on pharmacognostic specification and quantitative analysis of quercetin and quercitrin in B. malabarica leaves.

- The paracytic stomata and multicellular trichomes were found on lower epidermis of B. malabarica.

- Pharmacognostic parameters were shown the specific characteristics of $B$. malabarica leaf constant numbers.

- Quercetin and quercitrin contents were determined using RP-HPLC and method validation was in the acceptable range according to $\mathrm{ICH}$ guideline.

Cite this article: Thetsana P, Chaowuttikul C, Palanuvej C, Ruangrungsi N. Pharmacognostic Specifications, Quercetin and Quercitrin Quantification in Bauhinia malabarica Leaf. Pharmacog J. 2019;11(1):155-60. 